\title{
Relationship between Macula Pigment Optical Density and Visual Performances in Patients with dry Age related Macular Degeneration accompanied with Macula Drusens
}

\author{
Amila Chandrasekera ${ }^{1 *}$, Vidya Jayarathne ${ }^{1}$, Dasantha Fonseka ${ }^{1}$ \\ ${ }^{1}$ Optometrist, Vision Care Optical Services Pvt Ltd, N0:6, Ward Place, Colombo 7, Sri Lanka
}

Received: 02 November, 2016; Accepted: 28 November, 2016; Published: 07 December, 2016

*Corresponding author: Amila Chandrasekera, Diploma in optometry, Vision Care Optical Services Pvt LTD, No 6, Ward Place Colombo 7, Sri Lanka, Tel- +94782407249, +94777693951, +94112675034, Fax- +9411268 1173, +94 11533 4928; E-mail: emmysampath2@gmail.com

\begin{abstract}
Objectives: To determine the relationship between Macula Pigment Optical Density and Visual Performances (foveal sensitivity, Contrast sensitivity and stereo acuity) in patients with Dry Age Related Macular Degeneration accompanied with Macular Drusen.

To evaluate the awareness of patients about the condition

Methods: A descriptive cross sectional study according to convenience sampling was carried out with 80 patients (160 eyes) aged 44-65 for duration of 14 months. Data was recorded in each subject by carrying out a questionnaire including Demographic profile, Visual Functions; (Foveal sensitivity -measured by Humphrey Field Analyzer), Contrast sensitivity (by lea contrast acuity chart), stereo acuity (by TNO test).
\end{abstract}

Thickness of macula \& presence of drusen -measured by Cirrus 5000 spectral domain Optical Coherence Tomography and Macula pigment optical density by Zeiss Visucam 500 MPOD mode ,AMD was graded into 3stages by the presence of 15 or more macular drusen > $63 \mu \mathrm{m}$ and all were again divided in to 3 sub-groups according to MPOD levels[2]. All data were analyzed using SPSS software.

Results: Mean MPOD levels in 160 subjects, Stage- $1-0.41$ Stage-2 -0.31 , Stage- $3-0.17$

Mean Foveal sensitivity (MFS); low range $=15 \mathrm{~dB}$, mid-range $=21$, high-range $=26 \mathrm{~dB}$, Mean Contrast sensitivity; low-range $=25 \%$, midrange $=5 \%$, high-range $=2.5 \%$ and Mean Stereo acuity; low range $=480$ sec of arc, mid-range $=240 \mathrm{sec}$ of arc high-range $=60 \mathrm{sec}$ of arc.

Patients awareness score $-7 / 7=10 \mathrm{pt}, \quad 7 / 6=0 \mathrm{pt}, 7 / 5=12 \mathrm{pt}$ $7 / 4=8 \mathrm{pt}, 7 / 3=15 \mathrm{pt}, 7 / 2=16 \mathrm{pt}, 7 / 1=34 \mathrm{pt} 7 / 0=1105 \mathrm{pt}$.

Conclusion: People aged 45-65 with drusen maculopathy was found with a significant relationship of decreasing macula pigments (lower MPOD values), as a result of it they are at a considerable risk of decreased visual performances. $72.5 \%$ patients from the study group were totally unaware about the condition.

Keywords: Macula Pigment Optical Density; Age Related Macular Degeneration; Visual Performances

\section{Introduction}

Yellowish pigments composed of xanthophyll carotenoids Lutein ,Zeaxanthin and meso-zeaxathin which accumulates mostly around the center of the macular (fovea) are referred to macular pigments [1]. Lutein \& zeaxathin are dietary origin, Meso-zeaxathin is formed in the retina by conversion from lutein. The density or the thickness of the pigments in macular is called macular pigment optical density (MPOD). Age related macular degeneration (ARMD) is a disease which leads to appear changers or loss of centre vision. Studies have shown that the thickness of the macular pigments has a relationship to one's risk of developing Age Related Macular Degeneration [2-4].

There are two major functions of these pigments. It acts as an optical filter; the absorbance spectrum of macular pigments peak at $460 \mathrm{~nm}$, therefore it acts as a filter and absorbs the shortwave blue light and reduce the photochemical damage to the retinal pigment epithelium and the photoreceptors in the fovea [5]. Photochemical damage of blue light in macular can do functional changes including reduction in cones, leads to loss of centre vision which is a key sign in ARMD [5-8]. Having high macular pigment density protects the macular from harmful shortwave length light and reduces ARMD risk and lower density MPOD could put you at risk of damaging the cones from light rays which leads to ARMD [5-8].

Antioxidant properties of macular pigments; Retina is one of the highest oxygen supplied tissue in human body. Because of the higher levels of oxygen, exposure to radicals (ex: blue light) which increases the Reactive oxygen species generation, so the retina is highly suspect able for oxidative damage [911]. The macular pigments containing carotenoids which are well known for its antioxidative activities, acts as a Reactive oxygen species scavenger and protects the retinal pigment epithelium against photo oxidative damage $[10,11]$. So with a higher macular pigment density the oxidative damage is reduced and macular pigments protects the Retinal Pigment Epithelium 
being damaged. Excessive intracellular lipofuscin in RPE is known to contribute to drusen formation in ARMD [1,12-13]. Macular pigments are protecting the retina and retinal pigment epithelium from harmful blue light and light-initiated oxidative damage which may lead to age related macular degeneration. Because of these reasons Low macular pigment optical density becomes a high risk factor for ARMD.

ARMD is one of the leading causes for blindness among the elderly in the world. Currently 1.75 million of the population are affected,3 million population will be affected by 2020 [15] and 7 million population are at risk of developing advanced AMD, and 1 in 3 persons $\geq 70$ years old with early AMD will develop advanced disease over 10 years [14,15].

According to the study done by J. Loughman, P.A. Davison in 2010 shows the contribution of Macula Pigments to visual performance and experience [16, 17]. Several studies have reported, that MP may play a key role in visual health through a complex interplay between the optical, neurological and physiological mechanisms underlying vision.

Studied by BR Hammond Jr, BR Wooten have reported that MP may play a key role in visual health, amongst normal subjects [18].

G. Carboni, G. Forma, in 2010 showed an association of better dark adapted cone sensitivities in higher MPOD values [19].

There are many variables that have been investigated about MPOD and the functional visual changers, no research or studies have been done with Sri Lankan or south Asian sample (ARMD affected) regarding this topic.

The objective of this study is to determine the relationship between Macula Pigment Optical Density and Visual Performances such as Foveal sensitivity, Contrast sensitivity and Stereo acuity in patients with dry ARMD accompanied with macular drusen and to evaluate the awareness of patients about the condition.

\section{Methods}

\section{Participants}

A descriptive cross sectional study according to convenience sampling was carried out at Vision Care Optical Services pvt Ltd, No 6 ward place Colombo 7, form 2015 January -2016 April .Participants were 80 Sri Lankan adults (160 eyes), 40 males and 40 females age range from 45 to 65 years, who were diagnosed with Drusen Maculopathy after a complete ophthalmological examination including Optical Coherence Tomography. Subjects with any ocular pathology other than drusen maculopathy were excluded. All participants were given a full explanation of investigation procedures with the option to withdraw from the study at any time.

\section{Materials}

Data were recorded in each subject by carrying out a questionnaire. Questionnaire was divided into four parts; first part was for social demographic data which include age, gender, marital status and area of residence. Second part was for personal health and medical status which include level of blood sugar, blood pressure levels, body mass index, cholesterol levels, family history of ocular or other diseases, past ocular/ systemic medical and surgical history, current ocular/systemic medications, history of habits- alcoholic/smoking etc. Third part was for visual performances which include foveal sensitivity, contrast sensitivity and stereo acuity. Forth was for retinal status which includes number of drusen, ARMD level and MPOD level, last part include seven questions about the disease and score of corrected answers.

Thickness of macula \& presence of drusen was measured by Cirrus 5000 spectral domain Optical Coherence Tomography by Carl Zeiss Meditec with acquired HD 5 line and 512x128 macula cube scans, reports with signal strength less than 6 were excluded. Macula pigment optical density (MPOD) was measured using Visucam 500 by Carl Zeiss Meditec on (MPOD) mode. Foveal sensitivity by-Humphrey Field Analyzer (HFA 3by Carl Zeiss Medi tec) - in fovea on mode with stimulus-3 target size on white background with the calculation of refractive correction according to spectacle power and age, Contrast sensitivity by lea contrast acuity chart in a standard room illumination and stereo acuity by TNO test while patient wear red-green goggles in a standard room illumination at a constant $40 \mathrm{~cm}$ distance.

\section{Procedure}

AMD was graded into three stages by the presence of 15 or more macular drusen $>63 \mu \mathrm{m}$ (measured by OCT) adoring to (Macular Pigment Density Measurement in Patients with age-related Macular Degeneration Jens Dawczynski1, Susanne Jentsch 2, Dietrich Schweitzer 2, Martin Hammer 2, Jürgen Strobel 3)1st stage - Less than 5 macular drusen $>63 \mu \mathrm{m}$, 2nd stage - 5-15 macular drusen $>63 \mu \mathrm{m}$, 3rd stage - More than 15 macular drusen $>63 \mu \mathrm{m}$.

All subjects were again divided in to 3 sub-groups according to MPOD levels [2]. Sub groups were graded as; Low range MPOD levels $0-0.21$, Mid-range MPOD level 0.21-0.44, High range MPOD level 0.45 - 1.0.

In every sub group Probability value with visual functions was calculated to determine a relationship. All statistical analyses were performed using the Statistical Package for the Social Sciences by IBM Company, Chicago, IL

\section{Results}

160 eyes from 80 patients (40males and 40 females) who were diagnosed with drusen maculopathy were included in this study and were graded in to three stages of ARMD,

Table 1 summarises the mean MPOD level in each ARMD stage; Stage 1 mean MPOD $=0.41$, Stage 2 mean MPOD $=0.31$, Stage 3 mean MPOD $=0.17$. Lowest values of 0.05 and highest of 0.65 densities were found among the group.

All subjects were divided in to three sub groups according to MPOD levels and calculated with visual performances to determine relationships. Significant changes in visual performances were found with the results. 
Table 2 shows the consecutive change in foveal sensitivities in different MPOD levels, Mean Foveal sensitivity in (MFS); low range MPOD group $\mathrm{mFS}=15 \mathrm{~dB}(\mathrm{p}=0.0014)$, mid range MPOD group $m F S=21 \mathrm{~dB}(\mathrm{p}=0.0019)$, high range $M P O D$ group $\mathrm{mFS}=26 \mathrm{~dB}$ $(p=0.0041)$, all result shows significant values $p>0.05$.

Table 3 shows the changers in contrast sensitivity in different MPOD levels ,Mean Contrast sensitivity (mCS); low range MPOD group $\mathrm{mCS}=25 \%+/-2$ optotypes in lea contrast acuity chart $(\mathrm{p}=0.0003)$, mid range MPOD group $\mathrm{mCS}=5 \%+/-3$ optotypes $(\mathrm{p}=0.0042)$, high range MPOD group $\mathrm{mCS}=2.5 \%+/-2$ optotypes $(\mathrm{p}=0.0048)$.

Table 4 shows the changers in stereo acuity in different MPOD levels, Mean Stereo acuity (mSA); low range MPOD group $\mathrm{mSA}=480 \mathrm{sec}$ of $\operatorname{arc} 9(\mathrm{p}=0.0672)$, mid range MPOD group $\mathrm{mSA}=240 \mathrm{sec}$ of $\operatorname{arc}(\mathrm{p}=0.0005)$, high range MPOD group $\mathrm{mFS}=60 \mathrm{sec}$ of $\operatorname{arc}(\mathrm{p}=0.0012)$.

Part E in questionnaire- [Figure 1] summarises the patient's awareness score about the disease. One patient scored seven correct answers out of seven questions (7/7), no one scored $6 / 7$, two patients scored $4 / 7$, two scored $7 / 3$, four scored $3 / 7$, thirteen scored $1 / 7$ and one hundred thirty six scored $0 / 7$. $72.5 \%$ patients from the study group were totally unaware about the condition.

\section{Discussion}

The ARMD level increases (increasing the number of drusen) with decreasing densities of Macula Pigments was noticed in

Table 1: Results of Mean MPOD level vs ARMD stage

\begin{tabular}{|c|c|c|}
\hline MPOD level & $\begin{array}{c}\text { Man Foveal } \\
\text { Sensitivity (decibels ) }\end{array}$ & $\begin{array}{c}\text { Statistical } \\
\text { significance p= }\end{array}$ \\
\hline Low range - MPOD 0-0.21 & 15 & 0.0014 \\
\hline Mid range - MPOD 0.21-.044 & 21 & 0.0019 \\
\hline High range - MPOD 0.45-1.0 & 26 & 0.0041 \\
\hline
\end{tabular}

Mean MPOD levels in total 160 subjects; Stage 1 mean MPOD $=0.41$,

Stage 2 mean $\mathrm{MPOD}=0.31$, Stage 3 mean $\mathrm{MPOD}=0.17$

Table 2: Results from the Mean foveal sensitivity in different MPOD levels

\begin{tabular}{|c|c|c|}
\hline MPOD level & $\begin{array}{c}\text { Mean Contrast } \\
\text { Sensitivity } \\
\mathbf{( \% )}\end{array}$ & $\begin{array}{c}\text { Statistical } \\
\text { significance } \mathbf{p}=\end{array}$ \\
\hline Low range - MPOD 0-0.21 & 25 & 0.0003 \\
\hline Mid range - MPOD 0.21-.044 & 5 & 0.0042 \\
\hline High range - MPOD 0.45-1.0 & 2.5 & 0.0048 \\
\hline
\end{tabular}

Table 3: Results from the Mean Contrast sensitivity in different MPOD levels

\begin{tabular}{|c|c|c|}
\hline MPOD level & $\begin{array}{c}\text { Mean Stereo Acuity } \\
\text { (sec of arc) }\end{array}$ & $\begin{array}{c}\text { Statistical } \\
\text { significance p= }\end{array}$ \\
\hline Low range - MPOD 0-0.21 & 480 & 0.0672 \\
\hline Mid range - MPOD 0.21-.044 & 240 & 0.0005 \\
\hline High range - MPOD 0.45-1.0 & 60 & 0.0012 \\
\hline
\end{tabular}

Table 4: Results from the Mean foveal sensitivity in different MPOD levels

REF NO:

Research Questionnaire

Relationship between Macula Pigment Optical Density and Visual Performances in Patients with Drusen Maculopathy

Part A : Social Demographic data

\begin{tabular}{|l|l|l|l|l|}
\hline A.1. & A.2. & A.3. & A.4. Marital & A.5. Area of residence \\
Age & Gender & Occupation & Status & \\
\hline
\end{tabular}

Part B : Personal health

\begin{tabular}{|l|l|l|l|}
\hline $\begin{array}{l}\text { 2.1 DM+ } \\
\text { FBS RBS } \\
\text { HbA1C }\end{array}$ & 2.2. HTN- BP- & $\begin{array}{l}\text { 2.3. Wight- } \\
\text { Height- } \\
\text { y/n- }\end{array}$ & Obese \\
\hline $\begin{array}{l}2.5 \\
\text { Asthma }\end{array}$ & 2.6. Smoking & $\begin{array}{l}\text { 2.7. Hi LDL } \\
\text { Cholesterol }\end{array}$ & 2.8. Others \\
\hline $\begin{array}{l}\text { 2.9.Past } \\
\text { Ocular } \\
\text { History }\end{array}$ & $\begin{array}{l}\text { 2.10. Current } \\
\text { ocular medication }\end{array}$ & 2.11. Past medical/surgical history \\
\hline
\end{tabular}

\begin{tabular}{l|l} 
2.12. Family History & 2.13. Current medications (non-ocular)
\end{tabular}

Part C : Visual performances assessment

3.1 Foveal Sensitivity

-Humphrey field analyzer 3.2 Stereo acuity R/E L/E

R/E L/E

3.3 Visual acuity Distance

-snellens $\quad$ R/E 3.4 Near- N notations R/E L/E

$\mathrm{L} / \mathrm{E}$

3.5 Contrast Sensitivity

R/E L/E $\quad 3.6$ Color vision- Ishihara R/E L/E

Part D : Retinal status

4.1 No of drusen (more than $63 \mu \mathrm{m}$ ) - Visucam 500/Cirrus 500 OCT R/E L/E

\begin{tabular}{l|l} 
4.2 Dry ARMD level & 4.3 MPOD LEVEL -Visucam $500 \quad$ R/E
\end{tabular}

R/E L/E L/E

Part E: awareness about the condition

Do you know the name of your eye condition? Yes/ No 1.a.) If yes What is it called as?

It affects to the vision - centrally/peripherally/overall /don't know

Vision is affected - gradually/suddenly/don't know

Is it reversible/controllable or irreversible? reversible/controllable/ irreversible/don't know 4.a )If reversible or controllable -What are the available options you know?

Name at least two risk factors for this condition?

Have you ever heard about Macula Pigments? Yes/No

Do you know that it has a direct relation with your eye condition (ARMD)? Yes /No

Total score- ...../7

this study and some previous studies also shows the equal results $[2,5,26]$. With the low pigment protection in the retina, generation of Reactive oxygen species peaks its responses to radicals e.g.-blue light, together with unsaturated fatty acids it causes intracellular lipofusion in Retinal pigment epithelium which leads to formation of drusens. But for changes of the macula pigments in normal population may have variable causes [28] such as age [20-22], dietary habits [23], and ethnicity [14, $15,24]$.

Studies have shown that Macula pigments have a direct 


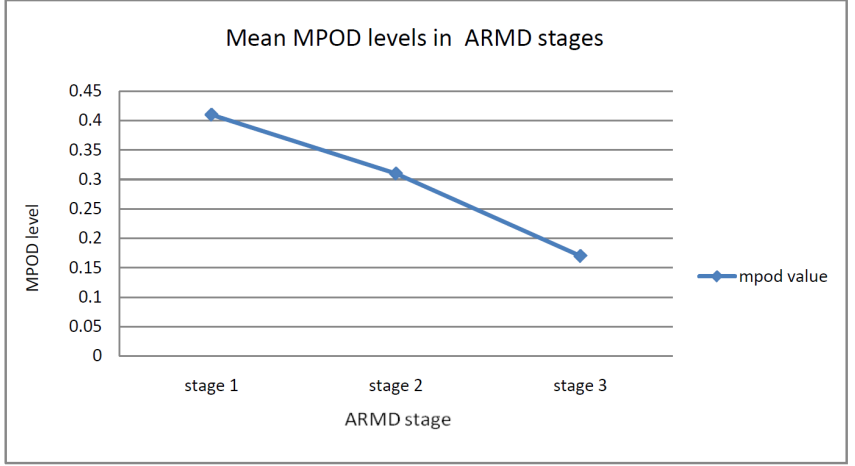

Figure 1: Shows the structure of the Questionnaire mentioned in Method of the study.

association in visual performances [17, 25-28]. Decreases of the macula pigment are associated with changes in visual performances. This study addresses the changes in three different visual functions in different levels of macula pigment optical densities.

Studies shows the Foveal sensitivity of normal population is around 29-37 dB [29-30]. A study done in 2012 [31] shows a correlation of macular pigment optical density with foveal threshold sensitivity in a healthy sample with a mean value of $30.72 \pm 1.56 \mathrm{~dB}$. Results of this study shows that foveal sensitivity significantly decreased in patients with drusen maculopathy with lowering of MPOD values. In to a mean value of $15 \mathrm{~dB}, 21 \mathrm{~dB}, 26 \mathrm{~dB}$ in-order to low, mid, high ranges of MPOD value. Previous studies have shown a strong correlation between Contrast sensitivity and Macula pigments [17,32] this study shows a significant decrease of contrast sensitivity with lowering of MPOD in $p>$ 0.05 and the results are consistent with J. Loughmans' findings in Macular pigment and its contribution to visual performance and experience [17]. Low range MPOD group shows very low levels of contrast sensitivity compared to other groups.

Stereo acuity plays one of major role in the explanation of grades of binocular vision. Authors of an article published in Optometry \& Vision Science July 2011- Volume 88 Issue 7 conclude that the stereo acuity increased with the higher levels of MPOD. In this study also stereo acuity significantly decreased with lowering of MPOD. Low values of stereo acuity was found in the patients with low MPOD levels in both the eyes as well as in the patients who have higher MPOD level in one eye but a lower level in the other eye because of the effect of binocularity.

As oxygen is essential for life of the cells and blue light is required for vision free radical damage is an unavoidable part of normal living but the studies have shown that MPOD values can increase with the dietary intake of lutain and zeaxanthin [33-38].

In Conclusion according to the study, Population aged 45-65 with dry ARMD accompanied with macula drusen was found to have a relationship of decreasing the macula pigments (lowering of MPOD values), so as a result of it they are at a considerable risk of decreasing the visual performances such as foveal sensitivity, Contrast sensitivity and Stereo Acuity. Awareness of the patients about the condition and prevalence is in very poor percentage. A leaflet was design and published to the public to increase the awareness and to control manifestations of loosing macula pigments and to control the decreasing rate of visual performances.

\section{Acknowledgments}

Mr P S J Chandrasekera, Mrs Kumari Fonseka, Dr Ganga Thennakoon, Ms Isuri Peiris, Ms Hasangi Hettige, all staff of Vsion care Optical services Pvt LTD

\section{References}

1. Eye Promise- Macular- pigment. [cited 2016]; Available from: http:// www.eyepromise.com/doctors/about/macular-pigment/

2. Nolan JM, Stack J, O' Donovan O, Loane E, Beatty S. Risk factors for age-related maculopathy are associated with a relative lack of macular pigment. Exp Eye Res. 2007;84(1):61-74.

3. Delori FC, Goger DG, Hammond BR, Snodderly DM, Burns SA. Macular pigment density measured by autofluorescence spectrometry: comparison with reflectometry and heterochromatic flicker photometry. J Opt Soc Am Opt Image Sci Vis. 2001; 18(6):1212-1230.

4. Landrum JT, Bone RA, Joa H, Kilburn MD, Moore LL, Sprague KE. A one year study of the macular pigment: the effect of 140 days of a lutein supplement. Exp Eye Res. 1997;65(1):57-62.

5. Loane E, Kelliher C, Beatty S, Nolan JM. The rationale and evidence base for a protective role of macular pigment in age-related maculopathy by British Journal of Ophthalmology. 2008;92(9):11638. doi: 10.1136/bjo.2007.135566.

6. Dentchev T, Yao Y, Pratico D, Dunaief J. Isoprostane $\mathrm{F}_{2 \alpha}-\mathrm{VI}$, a new marker of oxidative stress, increases following light damage to the mouse retina by Molecular Vision. 2007;13:190-195.

7. Höh $\mathrm{AE}$, Ach $\mathrm{T}$, Amberger R, Dithmar S. Light exposition in vitreoretinalsurgery : I. Basics. Ophthalmologe. 2008;105(10):898900. doi: 10.1007/s00347-008-1794-z.

8. Nolan JM, Stringham JM, Beatty S, Snodderly DM. Spatial profile of macular pigment and its relationship to foveal architecture. IOVS. 2008;49(5):2134-42. doi: 10.1167/iovs.07-0933.

9. Loane E, Nolan JM, O’Donovan O, Bhosale P, Bernstein PS, Beatty S. Transport and retinal capture of lutein and zeaxanthin with reference to age-related macular degeneration. Surv Ophthalmol. 2008;53(1):68-81. doi: 10.1016/j.survophthal.2007.10.008.

10. Eamonn D O'Connell, John M Nolan, Jim Stack, David Greenberg, Janet Kyle, LeighAnne Maddock, et.al. Diet and risk factors for age-related maculopathy. American Journal of Clinical Nutrition. 2008;87(3):712722.

11. Drobek-Slowik M, Karczewicz D, Safranow K. The potential role of oxidative stress in the pathogenesis of the age-related macular degeneration (AMD). Postepy Hig Med Dosw. 2007;61:28-37.

12. Chris J Kennedy, Piroska E Rakoczy, Ian J Constable. Lipofuscin of the retinal pigment epithelium: A review. Eye.1995;9:763-771. doi:10.1038/eye.1995.192.

13. Katayoon B. Ebrahimi, James T. Handa. Lipids, Lipoproteins, and AgeRelated Macular Degeneration. Journal of Lipids. 2011;2011:14. doi: $10.1155 / 2011 / 802059$.

14. Congdon N, O'Colmain B, Klaver CC, Klein R, Munoz B, Friedman DS, 
et al. Causes and prevalence of visual impairment among adults in the United States. Archives of Ophthalmology. 2004;122(4):477-485.

15. DS Friedman, BJ O’ Colmain, B Muñoz, Tomany SC, McCarty C, de Jong PT, et al. Prevalence of age-related macular degeneration in the United States. Archives of Ophthalmology. 2004;122(4):564-572.

16.J. Loughman, P.A. Davison, J.M. Nolan, M.C. Akkali, S. Beatty. Macular pigment and its contribution to visual performance and experience by Journal of Optometry. 2010; 3(2):74-90. doi: 10.1016/S18884296(10)70011-X.

17. Leslie D. WebRN- Macular Degeneration.com Blog [cited 20082016];http://www.webrn-maculardegeneration.com/lutein-andzeaxanthin.html

18. BR Hammond Jr, BR Wooten. CFF thresholds:Relation to macular pigment optical density. Ophthalmic and Physiological Optics. 2005;25(4):315-319. doi: 10.1111/j.1475-1313.2005.00271.x.

19. G. Carboni, G. Forma, M.G. Mutolo, BJ Jennings, A. Iannaccone Cross-sectional correlations between macular pigment optical density (MPOD) and measures of macular function. Investigative Ophthalmology and Visual Science. 2010;1293-A105.

20.S Beatty, M Boulton, D Henson, H-HKoh, I J Murray. Macular pigment and age related macular degeneration. Br JOphthalmol. 1999;83(7):867-877. doi:10.1136/bjo.83.7.867.

21. Bird AC, Bressler NM, Bressler SB, Chisholm IH, Coscas G, Davis MD, et al. An international classification and grading system for age-related maculopathy and age-related macular degeneration. Surv Ophthalmol. 1995;39(5):367-374.

22. Ambati J, Ambati BK, Yoo SH, Ianchulev S, Adamis AP. Age-related macular degeneration: etiology, pathogenesis, and therapeutic strategies. Surv Ophthalmol. 2003;48(3):257-93.

23. Krishnadev N, Meleth AD, Chew EY. Nutritional supplements for agerelated macular degeneration. Curr Opin Ophthalmol. 2010;21(3):1849. doi: 10.1097/ICU.0b013e32833866ee.

24. Pipis A, Touliou E, Augustin AJ. Macular pigment optical density in a Central European population. Ophthalmic Surg Lasers Imaging Retina. 2013;44(3):260-7. doi: 10.3928/23258160-20130503-09.

25. Nolan JM, Stack J, O’ Donovan O, Loane E, Beatty S. Risk factors for age-related maculopathy is associated with a relative lack of macular pigment. Exp Eye Res. 2007;84(1):61-74.

26. Tsika C, Tsilimbaris MK, Makridaki M, Kontadakis G, Plainis S, Moschandreas J.Assessment of macular pigment optical density (MPOD) in patients with unilateral wet age-related macular degeneration (AMD). Acta Ophthalmol. 2011;89(7):573-8. doi: 10.1111/j.1755-3768.2011.02170.x.
27. Loughman J, Akkali MC, Beatty S, Scanlon G, Davison PA, O’Dwyer V. The relationship between macular pigment and visual performance. Vision Res. 2010;50(13):1249-56. doi: 10.1016/j.visres.2010.04.009.

28. Nolan JM, Loughman J, Akkali MC, Stack J, Scanlon G, Davison P, Beatty $S$. The impact of macular pigment augmentation on visual performance in normal subjects: COMPASS Vision Res. 2011;51(5):459-69. doi: 10.1016/j.visres.2010.12.016.

29. Ratra V, Ratra D, Gupta M, Vaitheeswaran K. Comparison between Humphrey Field Analyzer and Micro Perimeter 1 in normal and glaucoma subjects. Oman J Ophthalmol. 2012;5(2):97-102.

30. Midena E, Radin PP, Convento E, Cavarzeran F. Macular automatic fundus perimetry threshold versus standard perimetry threshold. Eur J Ophthalmol. 2007;17(1):63-8.

31. Koushik R. Sargod, Rohit Shetty, Rajesh S. Kumar, Bhujang K. Shetty. Correlation of Macular Pigment Optical Density with foveal threshold sensitivity and Optical Quality in Normal Asian Indian Eyes. Investigative Ophthalmology \& Visual Science. 2012; 53:3378.

32. Alessandro I, Giovannella C, Gina F, Maria Giulia M, Barbara J.J. Macular Pigment Optical Density and Measures of Macular Function:TestRetest Variability, Cross-Sectional Correlations, and Findings from the Zeaxanthin Pilot Study of Response to Supplementation (ZEASTRESSPilot). Foods. 2016;5(2):32. doi:10.3390/foods5020032.

33. Michael D, Twa Birmingham. Optometry \& Vision Science. July 2011; 88 (7)p A1. doi: 10.1097/OPX.0b013e318225c772.

34. Curran-Celentano J, Hammond BR Jr, Ciulla TA. Relation between dietary intake, serum concentrations, and retinal concentrations of lutein and zeaxanthin in adults in a Midwest population. Am J ClinNutr. 2001;74(6):796-802.

35. Broekmans WM, Berendschot TT, Klöpping- Ketelaars IA, de Vries AJ, Goldbohm RA, Tijburg LB, et al. Macular pigment density in relation to serum and adipose tissue concentrations of lutein and serum concentrations of zeaxanthin. Am J Clin Nutr. 2002; 76(3):595-603.

36. Nolan JM, Stack J, O'connell E, Beatty S. The relationships between macular pigment optical density and its constituent carotenoids in diet and serum. Invest Ophthalmol Vis Sci. 2007;48(2):571-82.

37. Taylor HR, Muñoz B, West S, Bressler NM, Bressler SB, Rosenthal FS. Visible light and risk of age-related macular degeneration by Trans Am Ophthalmol Soc. 1990; 88:163-178.

38. Beatty S, Boulton M, Henson D, Koh HH, Murray IJ.. Macular pigment and age related macular degeneration. Br J Ophthalmol. 1999;83(7):867-877. 